Research Paper

\title{
Inhibition of protein PMP22 enhances etoposide- induced cell apoptosis by p53 signaling pathway in Gastric Cancer
}

\author{
Jingjing Hou ${ }^{1,2,3^{*}}$, Lin Wang ${ }^{1,2,3^{*}}$, Jiabao Zhao ${ }^{1,2,3^{*}}$, Huiqin Zhuo ${ }^{1,2,3^{*}}$, Jia Cheng ${ }^{1,2,3}$, Xin Chen ${ }^{1,2,3}$, Wei \\ Zheng ${ }^{1,2,3}$, Zhijun Hong ${ }^{1,2,3}$, Jianchun Cai ${ }^{1,2,3}$ \\ 1. Department of Gastrointestinal Surgery, Zhongshan Hospital of Xiamen University, Xiamen, Fujian 361004, China \\ 2. Institute of Gastrointestinal Oncology, Medical college of Xiamen University, Xiamen, Fujian 361004, China \\ 3. Xiamen Municipal Key Laboratory of Gastrointestinal Oncology, Xiamen 361004, Fujian, China \\ "These authors contributed equally to the work. \\ $\square$ Corresponding author: caijianchun@xmu.edu.cn. Department of Gastrointestinal Surgery, Zhongshan Hospital, Xiamen University, Xiamen 361004, Fujian, \\ China \\ (0) The author(s). This is an open access article distributed under the terms of the Creative Commons Attribution License (https://creativecommons.org/licenses/by/4.0/). \\ See http://ivyspring.com/terms for full terms and conditions.
}

Received: 2021.02.26; Accepted: 2021.07.06; Published: 2021.07.25

\begin{abstract}
Gastric Cancer (GC) is one of the main causes leading to death. PMP22, as a member of the GAS3 family of tetraspan proteins, it is associated with a variety of neurological diseases. Recently, more and more studies have shown that PMP22 play a great role in the physiological processes such as cells adhesion, migration, proliferation and tumorigenesis, but the involvement and functional mechanisms of PMP22 in Gastric carcinoma are not investigated clearly. In this study, we found that the PMP22 was overexpressed in the GC cells and tissue. Knockdown of PMP22 inhibits cell growth. Over-expressed PMP22 inhibits the etoposide-induced apoptosis, meanwhile knockdown of PMP22 promotes the etoposide-induced proliferation suppression, and increases cell apoptosis in GC cells. Furthermore, PMP22 enhanced the inhibition of the $p 53$ transcriptional activities and down-regulated the $p 53$ targeting genes, including $p 21$, BAX and PUMA with or without treatment of etoposide. Finally, our results showed that PMP22 reduced the etoposide-induced tumor growth suppression in nude mice. Taken together, our research provided an anti-apoptotic properties alternative mechanism for PMP22 in gastric carcinoma and suggested PMP22 can be a potential target for the treatment of gastric cancer.
\end{abstract}

Key words: PMP22, etoposide, p53, Apoptosis, gastric cancer

\section{Introduction}

The incidence and mortality of gastric cancer (GC) is the fifth most common digestive system cancer worldwide ${ }^{1}$ and is the third highest cause of cancer-related deaths in China ${ }^{2-5}$. Interactions between genetic and environmental elements promote aberrant activation of oncogenic signaling pathways that can accelerate cellular transformation and tumourigenesis ${ }^{2}$. Although there have been significant advances in GC treatment, the 5-year survival rate of GC remains less than 25 percent 2,4 . Given this, the molecular mechanism of GC should be investigated to improve clinical treatment, develop early diagnostic markers, and obtain new therapeutic options for GC patients ${ }^{4,6}$. However, the underlying molecular mechanisms of GC are largely unknown.

Apoptosis is one of the main types of programmed cell death (PCD) and plays important roles in cell and tissue homeostasis and in growth control 7, 8. Consequently, the deregulation of apoptosis is commonly associated with several kinds of diseases, including cancers ${ }^{8,9}$. P53 is an important protein that is involved in the process of apoptosis. As a transcription factor, p53 is mutated in most human cancers 10-12. Oncogenes, DNA damage, ionizing radiation, and chemotherapeutic agents including cisplatin and etoposide can increase p53 protein levels 
13, 14. To suppress cancer, $\mathrm{p} 53$ protein regulates the transcription of many different genes, including BAX, Puma, NOXA1, CDKN1A, and GADD45A, in response to a wide variety of stress signals including DNA repair, cell-cycle arrest, senescence, and apoptosis $9,11,13$. Mutations in tumors can make them resistant to apoptosis induction through the p53 pathway, therefore targeting apoptosis pathways is an attractive strategy for cancer therapy ${ }^{8}$.

Peripheral myelin protein 22 (PMP22) is a 22-kDa tetraspan glycoprotein, which is expected to predominantly expressed by myelinating Schwann cells and is closely related to Charcot-Marie-Tooth disease $(\mathrm{CMT})^{15,16}$. Several recent studies have shown that PM22 participates in cell proliferation and tumorigenesis in various cancers. However, the function of PM22 in tumors remains unclear. Several studies have indicated that PMP22 is a potential tumor suppressor 17-22, but other studies report a potential oncogenic function of PMP22 23-31. Overall, the involvement and functional mechanisms of PMP22 in gastric carcinoma are poorly understood.

To comprehensively study the function of PMP22 in apoptosis during gastric carcinogenesis, we examined PMP22 expression in GC tissue and a GC cell line. We found that PMP22 was overexpressed in GC tissue and knockdown of PMP22 inhibited cell proliferation. When we treated cells with the chemotherapy drug etoposide, PMP22 inhibited etoposide-induced apoptosis, and the knockdown of PMP22 promoted etoposide-induced suppression of proliferation and increased apoptosis in GC cells. Over-expressed PMP22 also inhibited p53 transcriptional activities and down-regulated expression of p53-targeting genes, including p21, BAX, and PUMA in the presence of etoposide. Our results revealed that PMP22 inhibits etoposide-induced cell apoptosis via activating the p53 signaling pathway in GC. These findings suggest that PMP22 exhibits anti-apoptotic properties in gastric carcinoma, and raise the possibility of PMP22 as a potential target for the treatment of gastric cancer.

\section{Material \& Methods}

\section{Plasmids construction}

Full-length cDNA encoding human PMP22 was amplified by PCR, the PCR product was sub-cloned into pLV-CMV, pCMV-HA vectors to get PMP22 overexpressing plasmids. Luciferase reporter plasmids PGL-3-p53 RE-luc, PGL-3-p21-luc and PGL-3-Bax-luc were kindly provided by professor Jiahuai Han (Xiamen University, Xiamen, China). All constructs derived from PCR products were verified by DNA sequencing.

\section{RNA interference}

The pLV lentiviral vector was used to express short hairpin RNA directed against the PMP22 or LacZ control sequence (GTCTCCGAACGTGTCA CGTT). Oligonucleotides targeting PMP22 (PMP22 shRNA-1, 5' - CCAAACTCAAACCAAACCAAA -3'; PMP22 shRNA-2, 5' - CGGTGTCATCTATGTGATCTT $\left.-3^{\prime}\right)$ were cloned into the pLKO.1 lentiviral vector. Recombinant lentiviral plasmids were cotransfected into $293 \mathrm{~T}$ cells with the packaging plasmids VSV-G, RSV-REV, and pMDL. After $48 \mathrm{~h}$ the viral supernatants were passed through $0.45-\mu \mathrm{m}$ filters and used to infect target cells in the presence of $8 \mu \mathrm{g} / \mathrm{ml}$ polybrene (Sigma-Aldrich).

\section{Cell culture, transfection and treatment}

The HGC27, SGC7901 and other human gastric cancer cell lines (GES, MKN28, AGS, MKN45, BGC823, MGC803) were purchased from the Institute of Cell Biology (Shanghai, China, http://www .cellbank.org.cn) and cultured in RPMI-1640 (Gibco, Life Technologies, NY, USA) supplemented with $10 \%$ fetal bovine serum (FBS, Excell), $100 \mathrm{U} / \mathrm{ml}$ penicillin and $100 \mu \mathrm{g} / \mathrm{ml}$ streptomycin (Gibco). Plasmid DNA transfection were performed with Turbofect reagent (Invitrogen, Carlsbad, CA, USA) according to the manufacturer's instructions. Etoposide was purchased from Sigma and was added to subconfluent cells at the indicated doses.

\section{Real-time quantitative PCR (qPCR)}

For qPCR analyses of mRNA, reverse transcription was performed with TRIzol (Invitrogen, Carlsbad, CA, USA) extracted total RNAs using a ReverTra Ace- ${ }^{\circledR}$ Kit as instructed (Toyobo, Tokyo, Japan). qPCR was performed using the SYBR Green Real-Time PCR Master Mix (Toyobo) and the Step One Plus Real-Time PCR system (Applied Biosystems Inc., Foster City, CA, USA) according to the manufacturers' protocols with primers showed in Table 1.

\section{Clinical samples}

All clinical samples were collected with the informed consent of the patients and study protocols that were in accordance with the ethical guidelines of the Declaration of Helsinki (1975) and were approved by the Institutional Medical Ethics Committee of Xiamen University. GC pathological diagnosis was verified by at least two pathologists. 40 human GC specimens and paired adjacent epithelial tissues were obtained from the Shanghai OUTDO BIOTECH CO., LTD. 


\section{Immunohistochemistry (IHC) analysis}

After deparaffinization, rehydration and antigen-retrieval, hepatic tissue slides $(4-7 \mu \mathrm{m})$ were blocked by $3 \% \mathrm{H}_{2} \mathrm{O}_{2}$ for 10 min and incubated with anti-PMP2 antibody (Abcam, Cambridge, MA, USA) at $4{ }^{\circ} \mathrm{C}$ overnight. The slides were then stained with horseradish peroxidase (HRP)-labeled IgG (Shanghai Long Island Biotec, Shanghai, China) at $25{ }^{\circ} \mathrm{C}$. Subsequently, the sections were stained with diaminobenzidine (DAB), counterstained with hematoxylin and washed in water. The immunoreactive cells were counted in five visual fields of each section under a $200 \times$ light microscope.

\section{Cell counting kit-8 (CCK-8) assay}

Relative cell viability of gastric cells treated with etoposide was detected with a CCK-8 kit (Dojindo, Kumamoto, Japan). Briefly, cells were plated into 96-well plates containing $100 \mu \mathrm{l}$ of growth medium, 48 $\mathrm{h}$ later, CCK-8 reagents $(10 \mu \mathrm{L} /$ well $)$ were added and incubated for $3 \mathrm{~h}$ at $37^{\circ} \mathrm{C}$ in a $5 \% \mathrm{CO}_{2}$ incubator. The absorbance was measured at $490 \mathrm{~nm}$. The cell viability was calculated as follows: relative cell viability $\%=\left[\left(A_{1}-A_{B}\right) /\left(A_{0}-A_{B}\right)\right] \times 100 \%, A_{1}$ is the absorbance of treatment group, $A_{0}$ is the absorbance of control group and $A_{B}$ is the absorbance of blank group.

\section{Colony formation assay}

Gastric cancer cells were first infected with pLV-Ctrl or pLV-PMP22 lentivirus or infected with pLKO-shCtrl, pLKO-shPMP22-1 or pLKO-shPMP22-2 lentivirus respectively, then $1 \times 10^{3}$ cells/well were seeded in 6-well plates with medium changed every two days, Cells were fixed with methanol and stained with violet after 10 days. Colonies were counted and analyzed for clonogenicity.

\section{Luciferase reporter assay}

SGC7901 cells or HGC27cells were transfected in 6-well dishes at $80 \%$ confluence with $0.5 \mu \mathrm{g}$ different reporters, together with other plasmids in different combinations as indicated. Each sample was supplemented with $0.5 \mu \mathrm{g}$ of pCMV5-LacZ, which expresses $\beta$-galactosidase, for monitoring the transfection efficiency. The cells were collected, and the luciferase activity was measured at $24 \mathrm{~h}$ after transfection. All transfections experiments were performed at least five times in triplicate, and the error bars represent SD of the means.

\section{Western blots}

Cells or tissues were lysed in a lysis buffer and protein concentrations for cells or tissues lysates were measured using the BCA protein assay kit (Thermo Fisher Scientific Inc., Waltham, MA, U.S) or G250
(Sigma-Aldrich, St. Louis, MO, USA). Thirty micrograms protein/lane whole cell lysates were electrophoresed in SDS-PAGE and transferred to a PVDF membrane (Millipore, Billerica, MA, USA). After blocking for $1 \mathrm{~h}$ at room temperature in TBST with $5 \%$ non-fat milk, the membranes were probed with the following primary antibodies: PMP22 (1:500 CST), actin (1:5000 Sigma). After washing three times, the membranes were incubated with HRP-conjugated goat anti-mouse or anti-rabbit secondary antibodies, 1:5000 (BD). Then, the chemiluminescence reaction was performed.

\section{Flow cytometry}

Apoptosis was measured using Annexin V-FITC/PI (Ebioscience, San Diego, USA) dual staining by flow cytometry. Briefly, SGC7901 cells $\left(2 \times 10^{5}\right.$ /well $)$ were seeded into 6-well plates and exposed to etoposide for 24 hours. Cells were harvested and washed in cold FACS buffer (PBS containing $2 \%$ FBS), and labeled with Annexin V-FITC for $30 \mathrm{~min}$ at $4^{\circ} \mathrm{C}$ in the dark and then with PI. The stained cells were analyzed by flow cytometry (LSRFortessa, Becton Dickinson, San Jose, CA, USA).

\section{Tumor xenografts}

Four to six-week-old male nude mice were obtained from the Laboratory Animal Center of Xiamen University. The animals were maintained on standard laboratory chow under a $12 \mathrm{~h} / 12 \mathrm{~h}$ light/dark schedule, unless otherwise indicated. All animal experiments were conducted according to protocols and guidelines approved by the Xiamen University Institutional Animal Care and Use Committee. A total of $6 \times 10^{6}$ control and SGC7901-PMP22 cells were subcutaneously injected into the dorsal flanks of nude mice, respectively. From day 10 after the injection of cells, the sizes of the tumors were measured every 4 days using a vernier caliper along two perpendicular axes. The volumes of the tumor were calculated using the formula: Volume $=$ Length $\times$ Width ${ }^{2} \times 0.52$.

\section{TCGA analysis}

We used mRNA expression array datasets from TCGA to explore gene expression profiles in human cancer. We downloaded data from 375 tumor tissues and 32 normal tissues of mRNA expression data to determine differences in transcription levels of FAK between normal gastric tissues and GC tissues. The data regarding mRNA expression were produced on the platforms of Illumina Infinium HumanMethylation450 BeadChip and IlluminaGA_RNASeqV2.1.0.0 (Illumina, Inc., San Diego, CA, USA). 
A

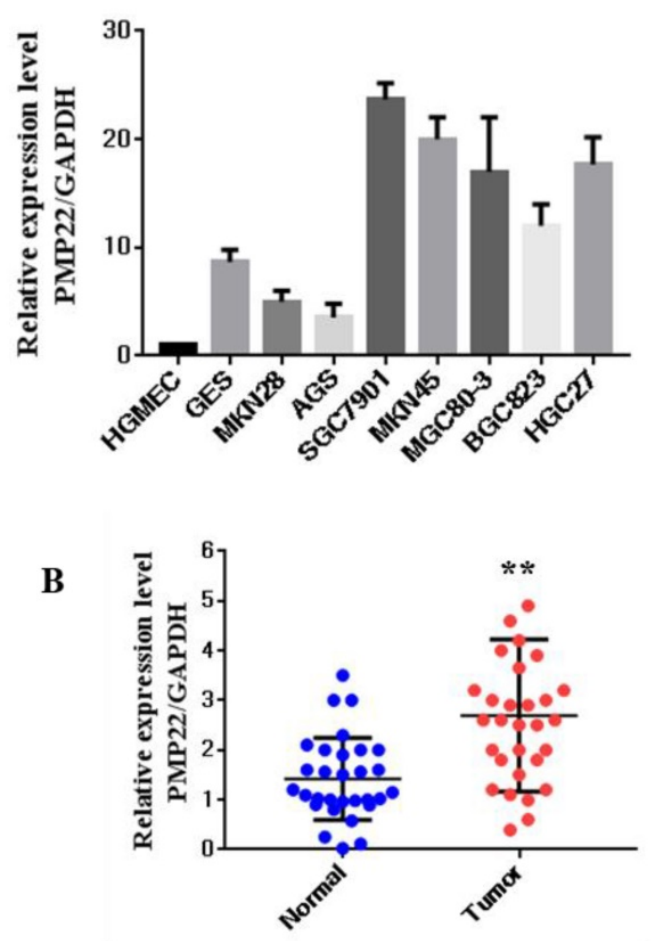

C

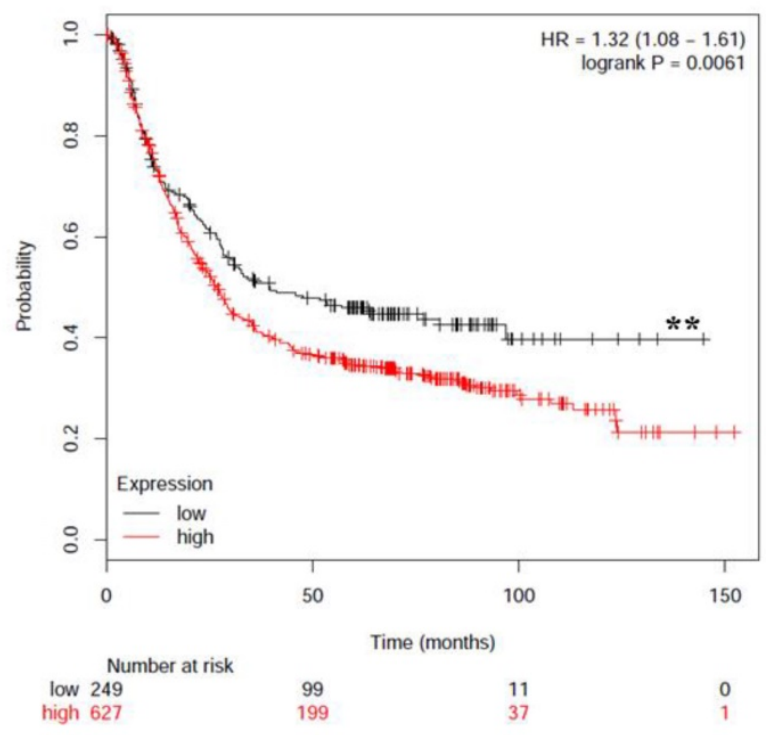

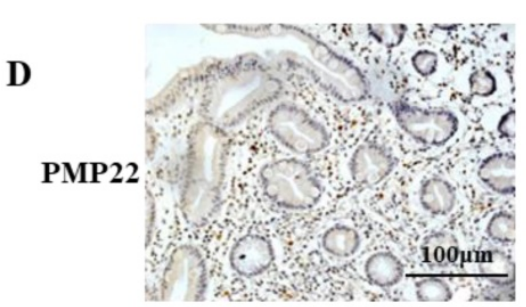

Normal

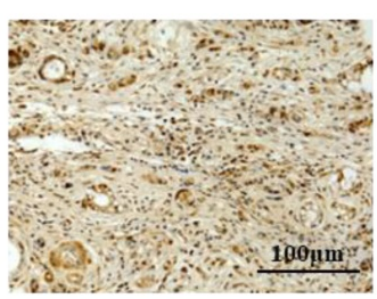

Tumor

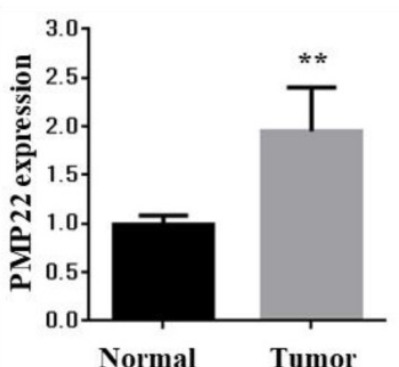

Normal Tumor

Figure 1. Expression of PMP22 in Gastric cancer (GC) tissues and cell lines. (A) The expression of PMP22 was detected using qRT-PCR in different GC cell lines (HGMEC, GES, MKN28, AGS, SGC7901, MKN45, BGC823, MGC803, and HGC27). (B) Kaplan-Meier survival curves for GC patients were plotted based on high or low PMP22 expression level. (C) The expression level of PMP22 was measured in 40 pairs of GC tissues and adjacent normal tissues by qualitative real-time reverse transcriptase PCR (qRT-PCR). Tumor, Gastric cancer tissue; Normal, adjacent noncancerous colon tissue; GAPDH mRNA were calibrated for qPCR analysis. (D) Immunohistochemistry results of PMP22 in human GC tissues. Results are representative of three independent experiments, and the error bars represent the SD. ${ }^{*} \mathrm{p}<0.05 ; * * \mathrm{p}<0.01$; $* * * \mathrm{p}<0.001$.

\section{Survival analysis}

Overall survival (OS) curve was calculated with the Kaplan-Meier method to evaluate the prognostic value of PMP22 mRNA expression in GC (Gastric Cancer). A total of 876 GC patients were recruited from the Kaplan-Meier Plotter online database. Subjects were split into two groups by median expression (high $v s$. low expression) and assessed by a Kaplan-Meier survival plots.

\section{Statistical analysis}

Values represent the mean \pm SD for at least three independent experiments. One-way ANOVA with Bonferroni's post-test was used for multiple comparisons and the Student's t test (two-tailed) was used for pair-wise comparisons. Correlation analyses were performed with Pearson's test. $P$ values $<0.05$ were considered statistically significant.

\section{Results}

\section{PMP22 is significantly upregulated in human gastric cancer cell lines and clinical samples}

PMP22 is well known as an integral membrane glycoprotein of the peripheral nervous system. To explore the function and relationship between the expression of PMP22 and gastric carcinogenesis, we first examined the expression of PMP22 in different gastric cell lines. As shown in Fig. 1A, compared with the expression level in a human glomerular microvascular endothelial cell line (HGMEC), PMP22 was upregulated in most of the gastric cancer cell lines. Next, the relative expression levels of PMP22 in the GC tissue group and the corresponding pathologically noncancerous gastric tissue group 
(control group) were evaluated by RT-PCR assay. PMP22 was significantly upregulated in comparison with normal tissues (Fig. 1C). Further analysis in Table 1 showed that PMP22 level was correlated to tumor-node-metastasis TNM staging $(\mathrm{n}=40, \mathrm{p}<$ $0.05)$, while no apparent association was found between PMP22 expression with patient gender, patient age, tumor size. The detailed description of the patient information is shown in Table 2 (Age, Tumor size, Clinical staging, etc.). As shown in Fig. 1B, overall survival (OS) curves were plotted using the Kaplan-Meier method based on the gene expression levels in 876 GC samples. Patients with higher levels of PMP22 had significantly shorter OS (Fig. 2A, logrank $p=0.0061$ ) than those with lower levels of PMP22. Immunohistochemical analysis also showed that significant expression of PMP22 in 29/48 (60\%) of GC tissues, with expression levels that were higher in GC than that in adjacent noncancerous gastric tissues (Fig. 1D). These results suggested that PMP22 may play an important role in GC development.

Table 1. The baseline characteristics of GC patients included $(n=$ 40)

\begin{tabular}{|c|c|c|c|c|}
\hline \multirow{2}{*}{$\begin{array}{l}\text { Clinicopathological } \\
\text { parameters }\end{array}$} & \multirow[b]{2}{*}{ Case } & \multicolumn{2}{|c|}{ PMP22-expression } & \multirow[t]{2}{*}{ P-value } \\
\hline & & low & high & \\
\hline \multicolumn{5}{|l|}{ age, years } \\
\hline$>=50$ & 22 & 9 & 13 & 0.5740 \\
\hline$<50$ & 18 & 3 & 15 & \\
\hline \multicolumn{5}{|l|}{ Gender } \\
\hline Male & 22 & 10 & 12 & 0.4852 \\
\hline Female & 18 & 2 & 16 & \\
\hline \multicolumn{5}{|l|}{ Tumor size } \\
\hline$>=4$ & 16 & 5 & 11 & 0.2587 \\
\hline$<4$ & 24 & 10 & 14 & \\
\hline \multicolumn{5}{|l|}{ TNM stage } \\
\hline T1-T2 & 17 & 6 & 11 & 0.0448 \\
\hline T3-T4 & 23 & 8 & 17 & \\
\hline \multicolumn{5}{|l|}{ LN Metastasis } \\
\hline $\mathrm{T} 1-\mathrm{T} 2$ & 15 & 4 & 11 & 0.0482 \\
\hline \multirow[t]{2}{*}{ T3-T4 } & 25 & 8 & 17 & \\
\hline & & 12 & 28 & \\
\hline
\end{tabular}

$\mathrm{P}<0.05$ represents significant differences.

Bold type indicates statistically significant difference.

\section{Downregulation of PMP22 suppressed gastric cancer cell proliferation}

To evaluate the effects of PMP22 on gastric carcinogenesis, we used a lentivirus system to knockdown of PMP22 in SGC7901 and HGC-27 cells (High expression of PMP22). SGC7901 and HGC-27 gastric cancer cells were infected with lentivirus expressing either pLKO-shCtrl or pLKO-shPMP22 for 72 hours, and then the mRNA expression levels of PMP22 were then determined by RT-PCR assay. As shown in Fig. 2A and Fig. 2C, compared to the control shRNA group, mRNA expression after PMP22 knockdown was reduced by $65 \%$ and $75 \%$, respectively in the SGC7901 cells $(p<0.001, p<0.01)$ and $70 \%$ in the HGC-27 cells $(p<0.001, p<0.01)$. The colony formation assay was next applied to examine the relative cell proliferation. As shown in Fig. 2B and Fig. 2D, proliferation was suppressed after downregulation of PMP22 by 70\% (SGC7901) and 75\% (HGC27) compared with the control group. Consistently, the CCK-8 assay results also showed reduced proliferation of shPMP22 cells compared with that of shCtrl cells ( $p<0.05$, vs control group) (Fig. 2E and Fig. 2F). Taken together, these results demonstrated that the inhibition of PMP22 significantly suppressed gastric cancer cell proliferation.

\section{PMP22 inhibits etoposide-induced cell apoptosis in gastric cancer cells}

Apoptosis plays a critical role in development and homeostasis 32, 33. To test whether PMP22 is related to the regulation of apoptosis, we used etoposide, a chemotherapeutic drug, to induce apoptosis. Annexin V-FITC assay was performed to investigate the effect of PMP22 on etoposide-induced apoptosis. The results in the Fig.3A illustrated that etoposide treatment alone resulted in a 30.6\% apoptotic rate, however, the percentage of apoptotic cells after etoposide treatment decreased to $17.5 \%$ upon overexpression of PMP22, while the percentage of apoptotic cells increased to about $50 \%$ after PMP22 silencing. Fig. 4B shows the corresponding values. The same result was also observed in another gastric cancer cell, HGC-27 (Fig. 3C-D). Compared to control cells, PMP22-overexpressing HGC27 cell lines presented reduced apoptotic cell death and the PMP22-knockdown HGC27 cell lines presented increased apoptotic cell death after etoposide treatment (Fig. 3C-D). These results suggested that PMP22 inhibited apoptosis in gastric cancer cells.

\section{PMP22 inhibits etoposide-induced cell apoptosis by inhibiting the transcriptional activity of $\mathrm{p} 53$}

Apoptosis is closely related to function of the p53 signaling pathway and our previous results showed that etoposide-induced N-Myc interacting protein (NMI) inhibited proliferation and promoted apoptosis by activating p53 signaling. To examine whether PMP22 affected the p53 signaling pathway and transcriptional activities of p53, we performed luciferase reporter assays in SGC7901 cells. The results showed that etoposide treatment enhanced activation of several p53-target genes, including p53 $\mathrm{RE}, \mathrm{p} 21$, and Bax, and overexpression of PMP22 significantly decreased the extent of activation by etoposide treatment (Fig. 4A-C). We also 
characterized the mRNA levels of p53-target genes, Bax, p21, and PUMA after overexpression of PMP22. The results showed that PMP22 overexpression decreased p53 transcriptional activities compared with the control groups with and without etoposide treatment (Fig. 4D-F), The western blots results showed that PMP22 inhibits etoposide-induced transcriptional activity of p53, and inhibits the cleavage of PARP (Fig. 4G).

We also performed luciferase reporter assays in SGC7901 cells with lentivirus expressing either pLKO-shCtrl or pLKO-shPMP22. In contrast to the result shown in Fig. 5A-C, knockdown of PMP22 increased the transcriptional activities of p53 RE, p21, and Bax (Fig. 6A-C), and RT-PCR assay also showed that knockdown of PMP22 significantly enhanced mRNA expression of these genes upon etoposide treatment (Fig. 5D-F). We also examined the protein expression of p53, p53 target gene p21, and Cleavage-PARP, the results showed that knockdown of PMP22 increases etoposide-induced transcriptional activity of p53, and increases the cleavage of PARP (Fig. 5G).
A

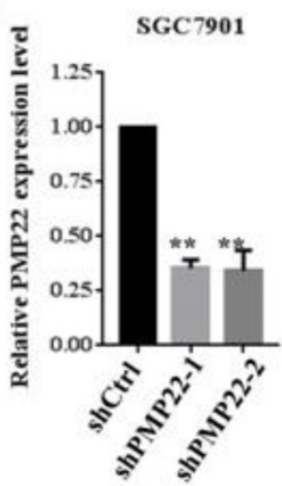

C

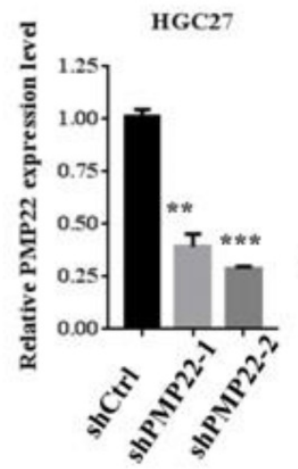

B

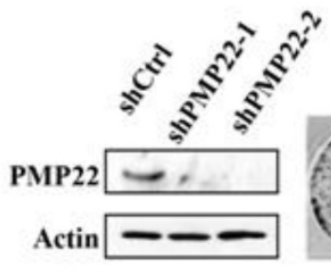

D
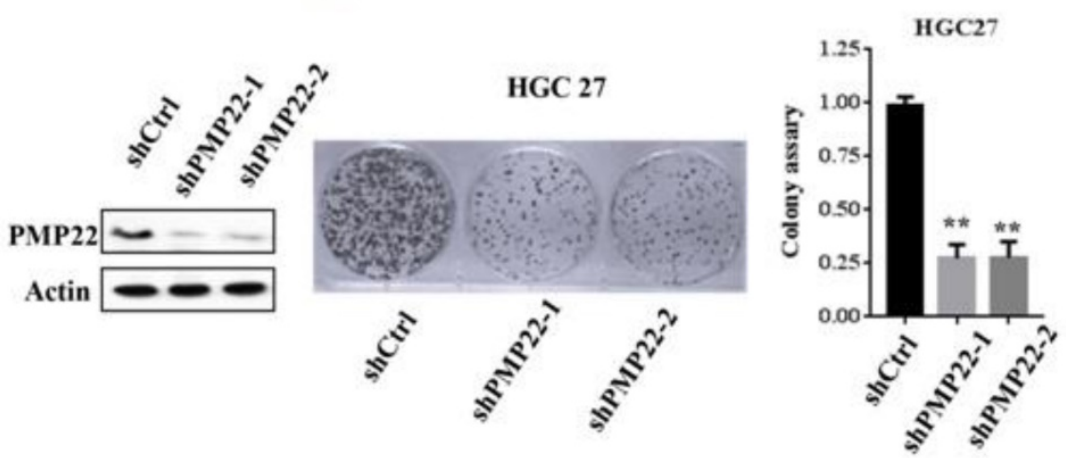

E

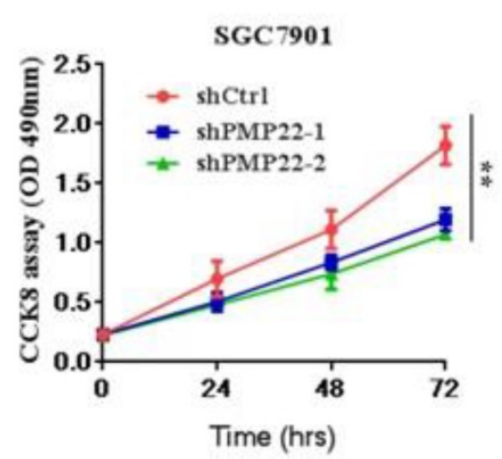

F

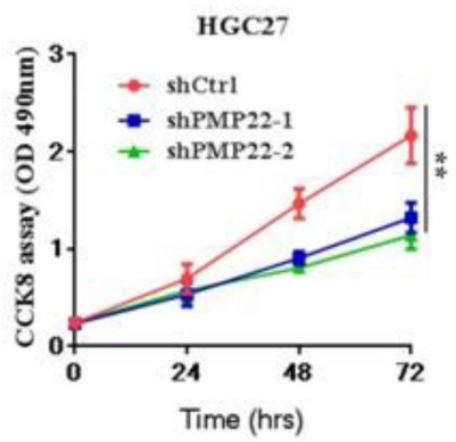

Figure 2. Knockdown of PMP22 inhibits cell growth and GC cell proliferation in vitro. (A) SGC7901 cells were infected with lentivirus expressing either pLKO-shPMP22 or pLKO-shCtrl for 72 hours and then the mRNA and protein expression levels of PMP22 were examined by q-PCR and Western blot. (B) Colony formation assay of SGC7901-shCtrl cells SGC7901-shPMP22 cells. (C) HGC27 cells were infected with lentivirus expressing either pLKO-shPMP22 or pLKO-shCtrl for 72 hours and the mRNA and protein expression levels of PMP22 were examined by q-PCR and Westerin blot. (D) Colony formation assay of HGC27-shCtrl cells and HGC27-shPMP22 cells. (E) Cell viability was determined in SGC7901-shCtrl cells and SGC7901-shPMP22 cells by CCK-8 assay. (F) Cell viability was determined in HGC27-shCtrl cells and HGC27-shPMP22 cells by CCK-8 assay. Statistical analysis of the CCK-8 assay results at $72 \mathrm{~h}$ shown in panel E. Results are representative of three independent experiments, and the error bars represent the SD. ${ }^{*} \mathrm{p}<0.05$; $* * \mathrm{p}<0.01 ; * * * \mathrm{p}<0.001$. 
Table 2. The detailed description of the GC patient tissues information $(n=40)$

\begin{tabular}{|c|c|c|c|c|c|c|}
\hline Number & Gender & Age & tumor size (diameter) & TNM stage & Pathological typing & Pathological typing \\
\hline 1 & Female & 74 & $\geq 4 \mathrm{~cm}$ & III & adenocarcinoma & Tubular adenocarcinoma \\
\hline 2 & Male & 45 & $<4 \mathrm{~cm}$ & III & adenocarcinoma & Low adhesion adenocarcinoma \\
\hline 3 & Female & 78 & $<4 \mathrm{~cm}$ & II & adenocarcinoma & Tubular adenocarcinoma \\
\hline 4 & Male & 39 & $\geq 4 \mathrm{~cm}$ & II & adenocarcinoma & Tubular adenocarcinoma \\
\hline 5 & Female & 68 & $<4 \mathrm{~cm}$ & IV & adenocarcinoma & Low adhesion adenocarcinoma \\
\hline 6 & Male & 57 & $\geq 4 \mathrm{~cm}$ & II & adenocarcinoma & Tubular adenocarcinoma \\
\hline 7 & Female & 50 & $<4 \mathrm{~cm}$ & IV & adenocarcinoma & mucosal adenocarcinoma \\
\hline 8 & Male & 58 & $<4 \mathrm{~cm}$ & III & adenocarcinoma & Tubular adenocarcinoma \\
\hline 9 & Male & 80 & $<4 \mathrm{~cm}$ & IV & adenocarcinoma & Tubular adenocarcinoma \\
\hline 10 & Male & 57 & $<4 \mathrm{~cm}$ & I & adenocarcinoma & Tubular adenocarcinoma \\
\hline 11 & Male & 43 & $\geq 4 \mathrm{~cm}$ & IV & adenocarcinoma & Low adhesion adenocarcinoma \\
\hline 12 & Male & 76 & $<4 \mathrm{~cm}$ & III & adenocarcinoma & Low adhesion adenocarcinoma \\
\hline 13 & Male & 43 & $<4 \mathrm{~cm}$ & III & adenocarcinoma & Tubular adenocarcinoma \\
\hline 14 & Male & 66 & $<4 \mathrm{~cm}$ & II & adenocarcinoma & Low adhesion adenocarcinoma \\
\hline 15 & Female & 49 & $<4 \mathrm{~cm}$ & III & adenocarcinoma & Tubular adenocarcinoma \\
\hline 16 & Female & 49 & $<4 \mathrm{~cm}$ & II & adenocarcinoma & mucosal adenocarcinoma, \\
\hline 17 & Female & 82 & $\geq 4 \mathrm{~cm}$ & III & adenocarcinoma & Tubular adenocarcinoma \\
\hline 18 & Male & 63 & $\geq 4 \mathrm{~cm}$ & II & adenocarcinoma & Tubular adenocarcinoma \\
\hline 19 & Female & 73 & $\geq 4 \mathrm{~cm}$ & III & adenocarcinoma & Papillary adenocarcinoma \\
\hline 20 & Male & 68 & $\geq 4 \mathrm{~cm}$ & II & adenocarcinoma & Tubular adenocarcinoma \\
\hline 21 & Female & 47 & $\geq 4 \mathrm{~cm}$ & IV & adenocarcinoma & Tubular adenocarcinoma \\
\hline 22 & Male & 64 & $\geq 4 \mathrm{~cm}$ & II & adenocarcinoma & Low adhesion adenocarcinoma \\
\hline 23 & Male & 49 & $\geq 4 \mathrm{~cm}$ & III & adenocarcinoma & Tubular adenocarcinoma \\
\hline 24 & Female & 70 & $\geq 4 \mathrm{~cm}$ & III & adenocarcinoma & Tubular adenocarcinoma \\
\hline 25 & Male & 46 & $\geq 4 \mathrm{~cm}$ & II & adenocarcinoma & Tubular adenocarcinoma \\
\hline 26 & Female & 47 & $<4 \mathrm{~cm}$ & III & adenocarcinoma & Papillary adenocarcinoma \\
\hline 27 & Male & 60 & $<4 \mathrm{~cm}$ & III & adenocarcinoma & mucosal adenocarcinoma, \\
\hline 28 & Female & 62 & $\geq 4 \mathrm{~cm}$ & IV & adenocarcinoma & Papillary adenocarcinoma \\
\hline 29 & Female & 47 & $<4 \mathrm{~cm}$ & II & adenocarcinoma & Tubular adenocarcinoma \\
\hline 30 & Female & 43 & $\geq 4 \mathrm{~cm}$ & III & adenocarcinoma & Tubular adenocarcinoma \\
\hline 31 & Male & 67 & $<4 \mathrm{~cm}$ & II & adenocarcinoma & Tubular adenocarcinoma \\
\hline 32 & Male & 59 & $<4 \mathrm{~cm}$ & I & adenocarcinoma & Tubular adenocarcinoma \\
\hline 33 & Male & 46 & $<4 \mathrm{~cm}$ & III & adenocarcinoma & mucosal adenocarcinoma, \\
\hline 34 & Female & 44 & $\geq 4 \mathrm{~cm}$ & II & adenocarcinoma & Tubular adenocarcinoma \\
\hline 35 & Male & 57 & $<4 \mathrm{~cm}$ & IV & adenocarcinoma & Tubular adenocarcinoma \\
\hline 36 & Female & 41 & $<4 \mathrm{~cm}$ & III & adenocarcinoma & mucosal adenocarcinoma, \\
\hline 37 & Female & 74 & $<4 \mathrm{~cm}$ & II & adenocarcinoma & Tubular adenocarcinoma \\
\hline 38 & Male & 48 & $<4 \mathrm{~cm}$ & IV & adenocarcinoma & Low adhesion adenocarcinoma \\
\hline 39 & Female & 45 & $<4 \mathrm{~cm}$ & II & adenocarcinoma & Tubular adenocarcinoma \\
\hline 40 & Male & 44 & $<4 \mathrm{~cm}$ & IV & adenocarcinoma & Low adhesion adenocarcinoma \\
\hline
\end{tabular}

\section{PMP22 inhibits etoposide-induced tumor growth suppression and knockdown of PMP22 enhances etoposide-induced tumor growth suppression in nude mice.}

To examine the effects of PMP22 in gastric cancer development in vivo, xenograft tumors were induced in nude mice by a single injection of SGC7901-Ctrl and SGC7901-PMP22 cells at a dosage of $5 \times 10^{6}$. After tumors reached 50 to $100 \mathrm{~mm}^{3}$ in size (15 days after implantation), mice were treated with PBS or etoposide every 3 days for 15 days. Tumor formation was monitored, and the tumor sizes were measured every 4 days. Thirty days after implantation, we observed that the sizes of xenograft tumors in mice injected with SGC7901-PMP22 cells were larger than the tumors in mice injected with SGC7901-Ctrl cells after treatment of etoposide, while the difference between the two groups treated with PBS was not very prominent (Fig. 6A-B) Consistent with this result, knockdown of PMP22 reduced tumor growth, and this inhibition was more obvious after etoposide treatment (Fig. 7A-B). As shown in Fig.7C, when treated with etoposide, the PMP22 overexpression group showed an increased tumor weight compared to the Ctrl group (Fig. 6C). Additionally, we observed that knockdown of PMP22 reduced tumor weight, and this inhibition was more obvious after etoposide treatment (Fig. 7C). The volume inhibition rate and tumor weight inhibition rate were statistically analyzed, as shown in Fig.6D and 7D. These data showed that the volume inhibition rate and tumor weight inhibition rate of the group that received from overexpressed PMP22 and etoposide treatment were both lower compared than those of the Ctrl group with etoposide. The knockdown of PMP22 increased both the volume inhibition rate and the tumor weight inhibition rate. Overall, our results demonstrated that PMP22 overexpression enhanced the tumorigenicity of gastric cancer cells and also inhibited etoposide-induced tumor suppression. 
A

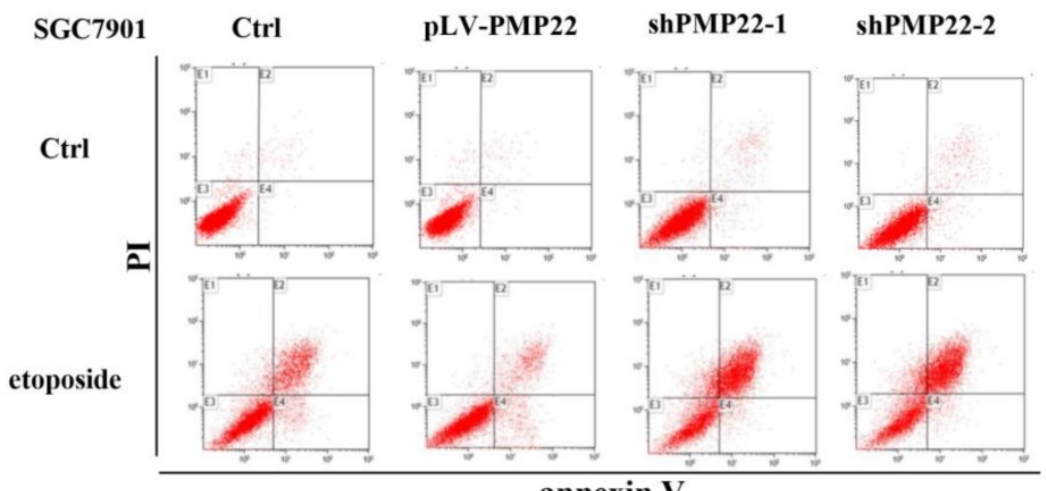

B

$\begin{array}{lc}\text { Treatment of Cells } & \text { Apoptosis(\%) } \\ \text { Ctrl } & 2.5 \\ \text { pLV-PMP22 } & 1.8 \\ \text { shPMP22-1 } & 5.2 \\ \text { shPMP22-2 } & 6.3 \\ \text { Ctrl+etoposide } & 30.6 \\ \text { pLV-PMP22+etoposide } & 17.5 \\ \text { shPMP22-1+etoposide } & 52\end{array}$

shPMP22-2+etoposide

C

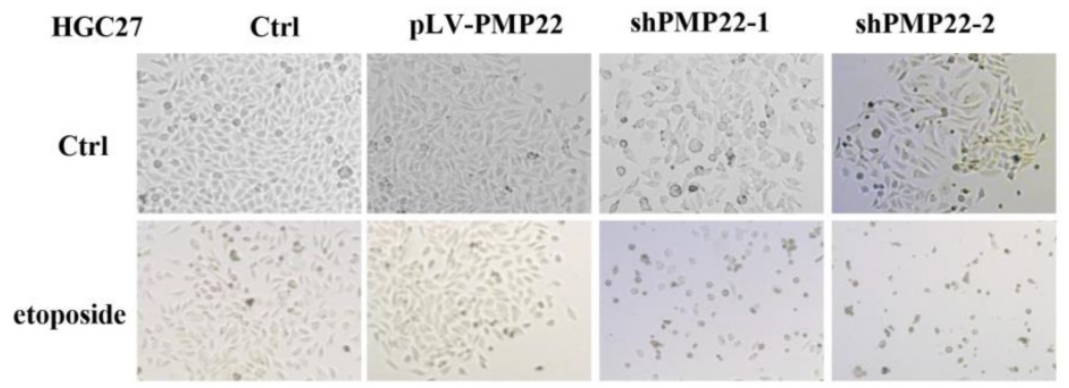

D

$\begin{array}{lc}\text { Treatment of Cells } & \text { Apoptosis(\%) } \\ \text { Ctrl } & 2.1 \\ \text { pLV-PMP22 } & 2.8 \\ \text { shPMP22-1 } & 15 \\ \text { shPMP22-2 } & 18 \\ \text { Ctrl+etoposide } & 34.6 \\ \text { pLV-PMP22+etoposide } & 19.3 \\ \text { shPMP22-1+etoposide } & 69 \\ \text { shPMP22-2+etoposide } & 80\end{array}$

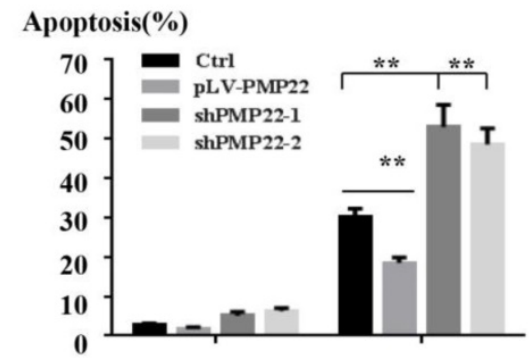

Apoptosis(\%)

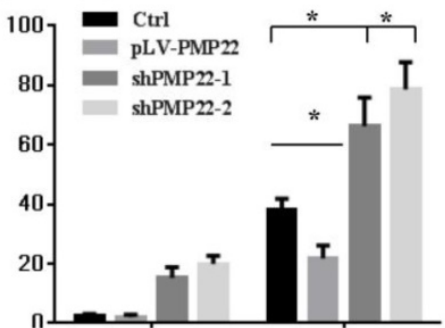

Figure 3. PMP22 inhibits etoposide-induced cell apoptosis. (A) Flow cytometry to assess cell apoptosis. After overexpression of PMP22 or knockdown of PMP22 in the SGC7901, cells were treated with PBS or etoposide for $12 \mathrm{~h}$. Cells were collected and apoptosis was examined by flow cytometry assay. (B) Statistical analysis of data presented in panel A. The apoptosis rates are shown. Results are representative of three independent experiments, and the error bars represent the SD. *p $<0.05$; ** $\mathrm{p}<0.01$; **** $\mathrm{p}<0.001$. (C). PMP22-overexpressing HGC27 cells (HGC27-PLV-PMP22) showed a decreased apoptotic morphology after etoposide treatment, and HGC27-shPMP22 cells showed an increased apoptotic morphology after etoposide treatment. The indicated cells were plated in 12-well plates. The next day, the cells were treated with etoposide for $12 \mathrm{~h}$, and the cells were imaged with a Nikon-TE2000 microscope. (D) Statistical analysis of images in panel C. $*_{p}<0.05 ; * * p<0.01 ; * * *_{p}<0.001$.

\section{Discussion}

Gastric carcinoma (GC) is a deadly malignancy afflicting about one million people worldwide, and the poor diagnosis and lack of effective therapies result in a low survival rate $1,3,4,34,35$. Although many studies have reported the diagnosis and treatment of gastric cancer, the underlying molecular mechanisms in GC development and progression remain unclear ${ }^{3,}$ 36,37 . Here, we show that PMP22 regulates gastric cancer cell proliferation by inhibiting cell apoptosis. Our results showed that: (1) PMP22 is significantly upregulated in human gastric cancer cell lines and clinical samples (Fig. 1); (2) Downregulation of PMP22 suppressed gastric cancer cell proliferation (Fig. 2); (3) PMP22 inhibits etoposide-induced cell apoptosis in 
gastric cancer cells (Fig. 3); (4) PMP22 suppressed p53 transcriptional activity upon etoposide treatment; (Fig. 4-5); (5) PMP22 enhanced tumorigenicity in vivo in nude mice and inhibited etoposide-induced tumor growth inhibition (Fig. 6-7). A possible pattern diagram was constructed, illustrating the potential molecular mechanism by which PMP22 regulates cell proliferation (Fig. 8). Collectively, our results demonstrate a novel anti-apoptotic role of PMP22 in the progression of gastric cancer, suggesting that
PMP22 might be an important diagnostic or therapeutic target for gastric cancers and other human diseases.

PMP22 is a tetraspan glycoprotein with proposed roles in peripheral nerve myelin formation. Duplication and deletion of the PMP22 gene is associated with Charcot-Marie-Tooth disease (CMT) and Hereditary Neuropathy with Pressure Palsies (HNPP) 15, 16, and several studies have shown that PMP22 regulates tumor development, metastasis, and
A

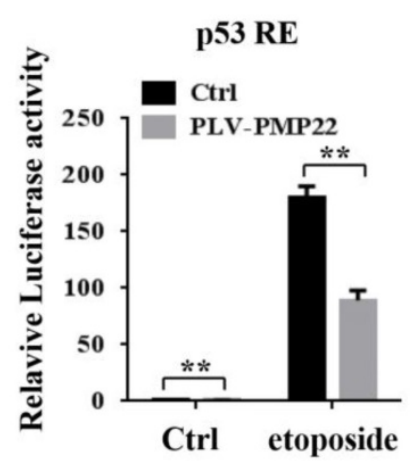

D

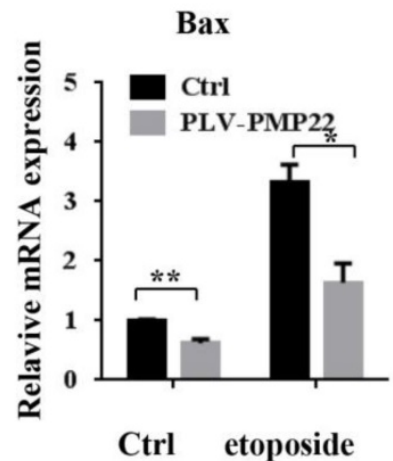

G

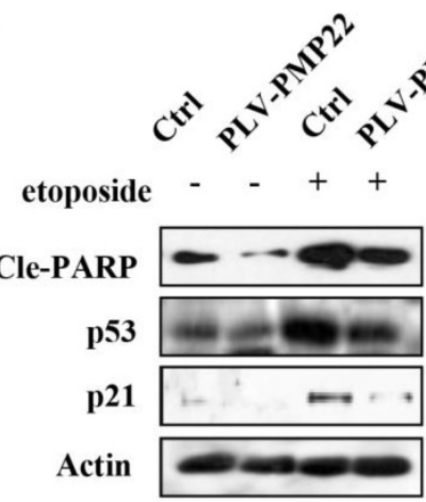

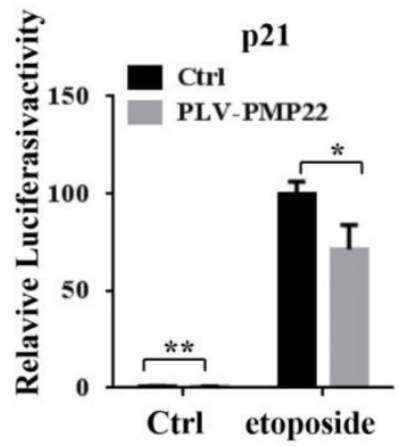

$\mathbf{E}$

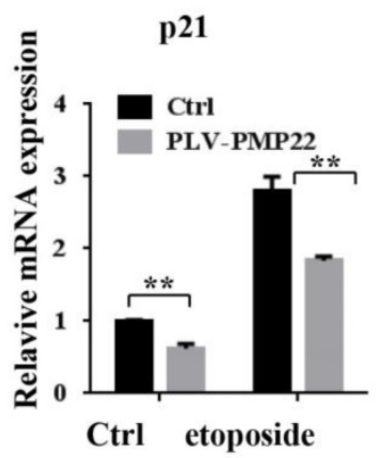

C

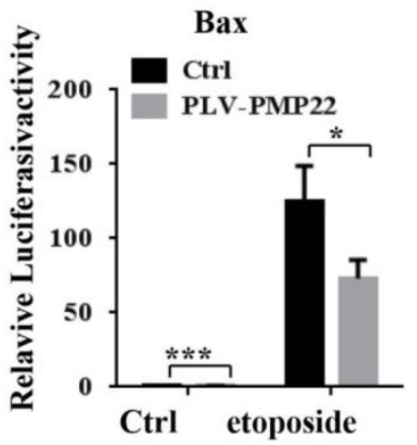

F

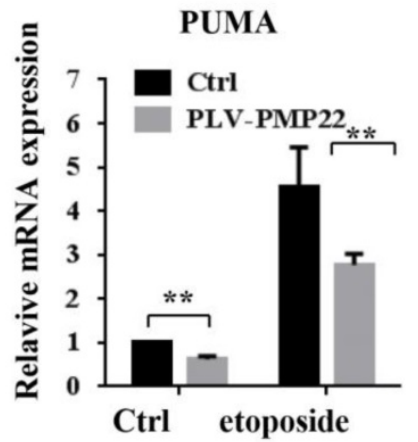

Figure 4. Overexpression of PMP22 represses the etoposide-induced activation of $p 53$ target genes. (A-C) Luciferase reporter assays of $p 53 R E$, $p 21$, and Bax. SGC7901-PLV-Ctrl or SGC7901-PLV-PMP22 cells were treated with or without etoposide, and then luciferase reporter assays were performed. (D-E) Analysis of Bax, P21, and PUMA mRNA expression by q-PCR. SGC7901-PLV-Ctrl or GC7901-PLV-PMP22 cells were treated with or without etoposide, and then assayed. (F) SGC7901-PLV-Ctrl or SGC7901-PLV-PMP22 cells were treated with or without etoposide, and then the expression of apoptosis-associated proteins were detected by western blots with anti-p53, 21 , Cle-PARP and Actin antibodies, and the expression of protein were quantified and statistically analyzed using image analyzer. (G) Statistical analysis of the protein expression showed in $(\mathrm{F})$. Results are representative of three independent experiments, and the error bars represent the SD. *P $<0.05$; **P $<0.01$; ***P $<0.001$. 
invasion in different cancers in addition to its functions in neurodevelopmental and neurological disorders ${ }^{17-28,} 30$. However, the role of PMP22 in tumorigenesis and metastasis has been incompletely understood. In a previous study, PMP22 was found using the Explorer Antibody Microarray to be a cell surface protein(s) marker of self-renewing property and chemoresistance ${ }^{31,38}$. Bortezomib was tested in mice as a PMP22 inhibitor in combination with DDP for chemoresistant gastric cancer therapy, and the results showed improved tumor inhibition effect of combination therapy compared to the drug alone ${ }^{31}$. In our study, we also found anti-apoptotic properties of PMP22, and inhibition of PMP22 strongly suppressed tumor proliferation in vitro and in vivo. We used a chemotherapy drug, etoposide, to induce cell apoptosis, and found that PMP22 inhibited etoposide-induced cell apoptosis. Consistent with this finding, inhibition of PMP22 increased cell proliferation in gastric cells and the nude mice. Therefore, PMP22 inhibition may be a good target for treatment of gastric cancer.
A

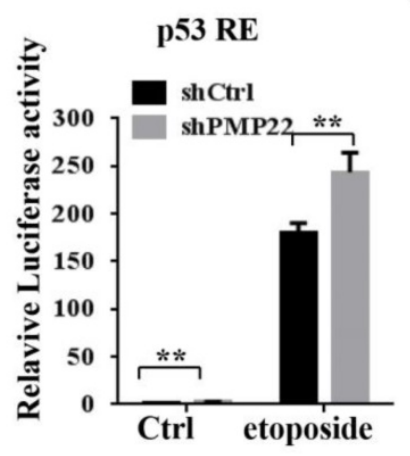

D

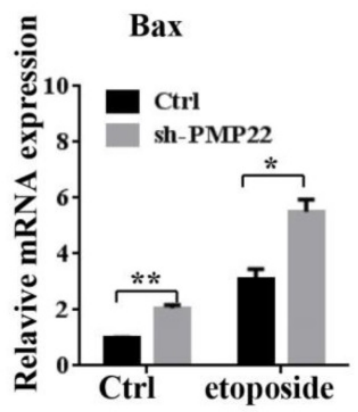

B

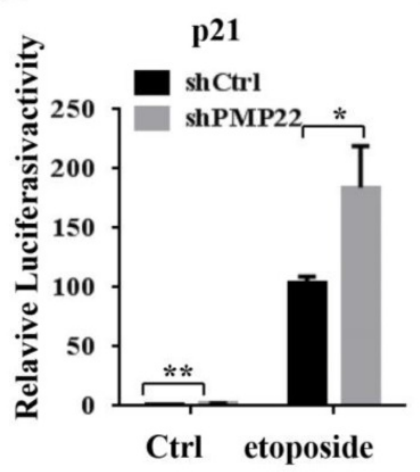

C

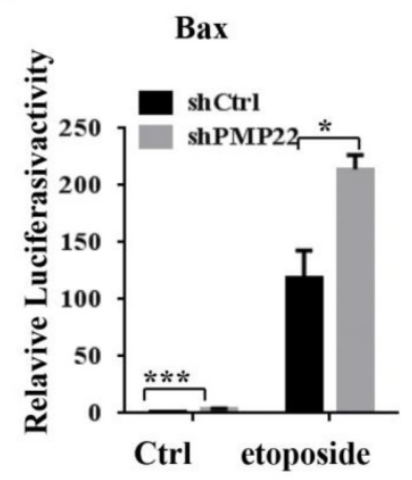

$\mathbf{F}$

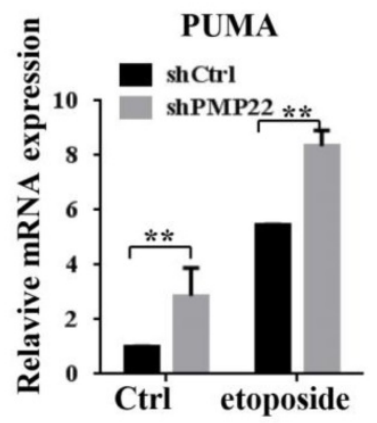

G

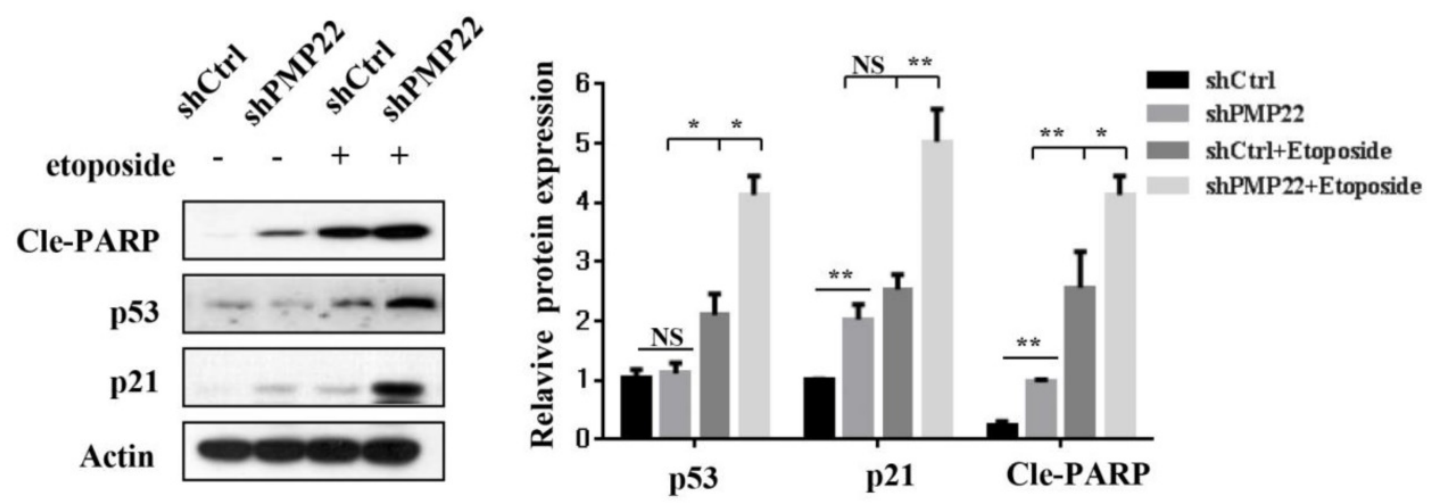

Figure 5. Knockdown of PMP22 increases the etoposide-induced activation of P53 target genes. (A-C) Luciferase reporter assays of p53RE, p21, and Bax. SGC7901-PLKO-shCtrl or SGC7901-PLKO-shPMP22 cells were treated with or without etoposide, and then luciferase reporter assays were performed. (D-E) Analysis of Bax, P21, and PUMA mRNA expression by q-PCR. SGC7901-PLKO-shCtrl or SGC7901-PLV-shPMP22 cells were treated with or without etoposide before qPCR. (F) SGC7901-PLKO-shCtrl or GC7901-PLKO-shPMP22 cells were treated with or without etoposide, and then the expression of apoptosis-associated proteins were detected by western blots with the indicated antibodies and quantified and statistically analyzed using image analyzer. (G) Statistical analysis of the protein expression showed in (F). Results are representatives of three independent experiments, and the error bars represent the SD. $* \mathrm{P}<0.05 ; * * \mathrm{P}<0.01 ; * * * \mathrm{P}<0.001$. 
A

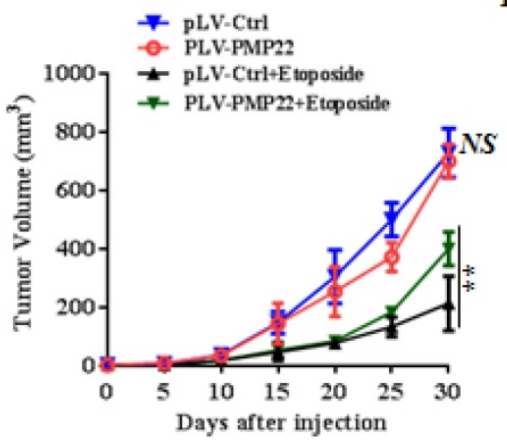

B

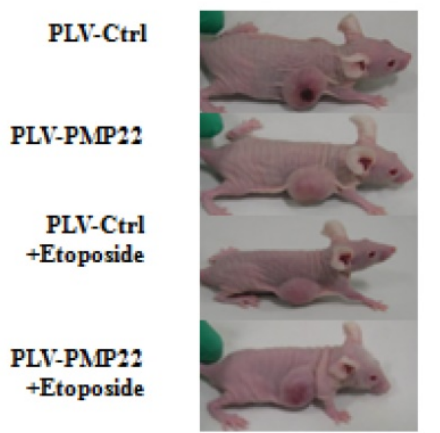

C

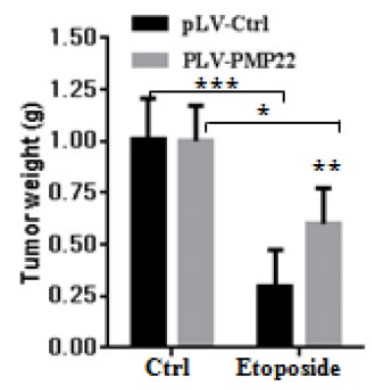

\begin{tabular}{ccccc}
\hline \multicolumn{5}{c}{ Indicators at day-30 $(p<0.05)$} \\
\hline $\begin{array}{c}\text { Group } \\
(\mathrm{n}=5)\end{array}$ & $\begin{array}{c}\text { Tumorvolume } \\
\left(\mathrm{mm}^{3}\right)\end{array}$ & $\begin{array}{c}\text { Tumor weight } \\
(\mathrm{g})\end{array}$ & $\begin{array}{c}\text { Tumor volume } \\
\text { inhibition } \%\end{array}$ & $\begin{array}{c}\text { Tumor weight } \\
\text { inhibition } \%\end{array}$ \\
\hline PLV-Ctrl & $780.22 \pm 50.35$ & $0.99 \pm 0.21$ & & \\
\hline PLV-PMP22 & $765.59 \pm 40.18$ & $0.97 \pm 0.18$ & 0.02 & 0.01 \\
\hline PLV-Ctrl+ Etoposide & $228.69 \pm 22.96$ & $0.25 \pm 0.09$ & 61 & 74 \\
\hline PLV-PMP22+ Etoposide & $408.29 \pm 18.54$ & $0.57 \pm 0.10$ & 45 & 43 \\
\hline
\end{tabular}

Figure 6. PMP22 reduces etoposide-induced tumor growth inhibition. (A) The tumor growth curve. SGC7901-Ctrl and SGC7901-PMP22 cells were inoculated into nude $\mathrm{BALB} / \mathrm{c}$ mice. After tumors reached 50 to $100 \mathrm{~mm} 3$ in size (15 days after implantation), mice were treated with PBS or etoposide every 3 days for 15 days. Tumor formation was monitored, and the tumor sizes were measured every 4 days. (B) Photographs of the xenograft from various groups of nude mice treated as indicated. (C) Statistical analysis of the tumor weight of each group. ${ }^{*} p<0.05 ;{ }^{*} p<0.01$. (D) Statistical analysis of the tumor volume inhibition rate and tumor weight inhibition rate ( $n=5$ ). ${ }^{*} p<0.05 ;{ }^{*} p<0.01$; $* * * p<0.001$.

A

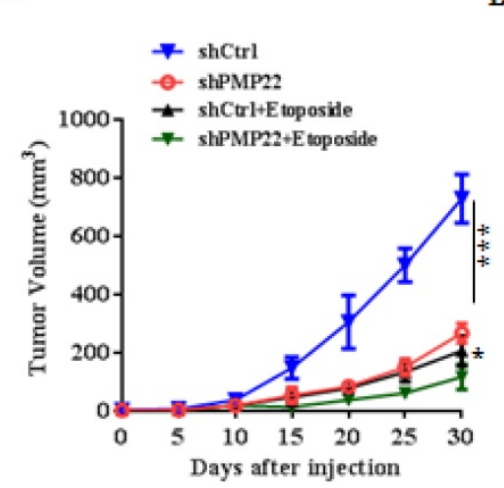

B

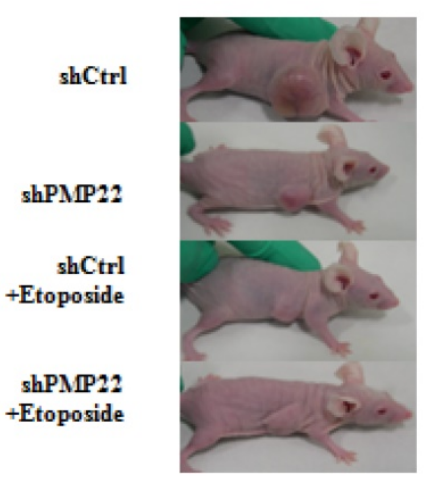

C

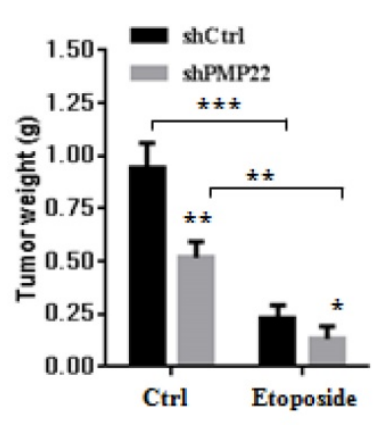

D

\begin{tabular}{ccccc}
\hline \multicolumn{5}{c}{ Indicators at day-30 $(p<0.05)$} \\
\hline $\begin{array}{c}\text { Group } \\
(\mathrm{n}=5)\end{array}$ & $\begin{array}{c}\text { Tumor volume } \\
\left(\mathrm{mm}^{3}\right)\end{array}$ & $\begin{array}{c}\text { Tumor weight } \\
(\mathrm{g})\end{array}$ & $\begin{array}{c}\text { Tumor volume } \\
\text { inhibition } \%\end{array}$ & $\begin{array}{c}\text { Tumor weight } \\
\text { inhibition } \%\end{array}$ \\
\hline shCtrl & $770.69 \pm 69.53$ & $0.94 \pm 0.15$ & & \\
\hline shPMP22 & $315.71 \pm 40.16$ & $054 \pm 0.09$ & 60 & 43 \\
\hline shCtrl+ Etoposide & $230.69 \pm 30.20$ & $0.23 \pm 0.11$ & 71 & 73 \\
\hline shPMP22+Etoposide & $161.71 \pm 10.16$ & $0.14 \pm 0.03$ & 81 & 85 \\
\hline
\end{tabular}

Figure 7. Knockdown of PMP22 increases etoposide-induced tumor growth inhibition. (A) The tumor growth curve. SGC7901-shCtrl and SGC7901-shPMP22 cells were inoculated into nude BALB/c mice. After tumors reached 50 to $100 \mathrm{~mm} 3$ in size (15 days after implantation), Mice were treated with PBS or etoposide for 15 days. Tumor formation was monitored, and tumor sizes were measured every four days. (B) Photographs of the xenograft from various groups of nude mice treated as indicated. (C) Statistical analysis of the tumor weight of each group. ${ }^{*} p<0.05,{ }^{* *} p<0.01$. (D) Statistical analysis of the tumor volume inhibition rate and tumor weight inhibition rate $(n=5)$. ${ }^{*} p<0.05$; $* * p$ $<0.01 ; * * *<0.001$ 


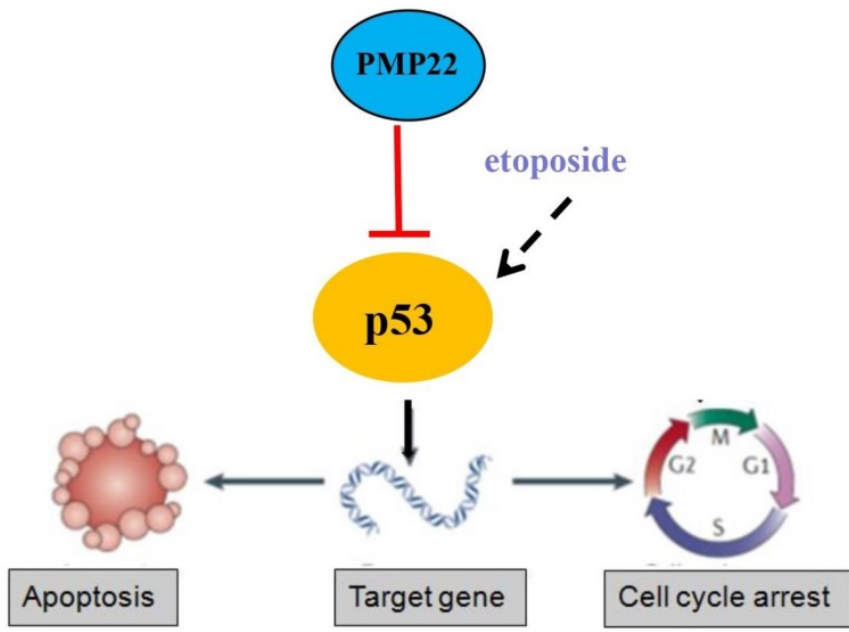

Figure 8. Proposed working model of PMP22 in the regulation of gastric cancer. PMP22 inhibits etoposide induced-cell apoptosis via $\mathrm{p} 53$ signaling pathway in gastric cancer.

In our results, we found that the effect of PMP22 overexpression on cell growth is not obvious (Supplemental Figures). It is possible that the expression of this protein itself is relatively high in tumor cells, however PMP22 inhibits etoposideinduced cell apoptosis after treatment of etoposide significantly. Knockdown of PMP22 inhibits cell growth and promotes the etoposide-induced proliferation suppression, and increases cell apoptosis in GC cells. Furthermore, PMP22 enhanced the inhibition of the p53 transcriptional activities and down-regulated the p53 targeting genes, including p21, BAX and PUMA with or without treatment of etoposide. In previous studies, PMP22 was reported to drive signal transduction away from the FAK/Src pathway and toward the AKT pathway, which reduced collagen gel contraction in ARPE-19 cells. Another study showed that Gas3/PMP22 expression was increased in apoptosis, that regulation of apoptosis by Gas3/PMP22 could regulate Schwann cell-differentiation ${ }^{39}$. Our results showed that PMP22 negatively regulated the p53 signaling pathway by inhibiting p53 target genes involved in apoptosis (BAX and PUMA) or cell cycle arrest (p21). However, the precise mechanism by which PMP22 regulates $\mathrm{p} 53$ is not clear. PMP22 is a tetraspan glycoprotein and p53 is locates on the cytoplasm and nucleus, therefore, they may not interact directly. The interactions of these two proteins require characterization.

\section{Supplementary Material}

Supplementary figure.

http://www.ijbs.com/v17p3145s1.pdf

\section{Acknowledgements}

This work was supported by grants from the
National Natural Science Foundation (81871979), Foundation of Xiamen Municipal Bureau of Science and Technology (Grant No. 3502Z20214ZD1034, 3502Z20184038), and Foundation of Fujian Provincial Department of Science and Technology (2019J01556).

\section{Abbreviations}

GC, Gastric Cancer 1; PCD, programmed cell death; PMP22, Peripheral myelin protein 22; CMT, Charcot-Marie-Tooth disease; HGMEC, human glomerular microvascular endothelial cell line; OS, overall survival; NMI, N-Myc interactor.

\section{Competing Interests}

The authors have declared that no competing interest exists.

\section{References}

[1] Siegel RL, Miller KD, Jemal A. Cancer statistics, 2018. CA Cancer J Clin. 2018; 68: 7-30.

[2] Soutto M, Chen Z, Bhat AA, et al. Activation of STAT3 signaling is mediated by TFF1 silencing in gastric neoplasia. Nat Commun. 2019; 10: 3039.

[3] Parkin DM, Bray F, Ferlay J, Pisani P. Global cancer statistics, 2002. CA Cancer J Clin. 2005; 55: 74-108.

[4] Nagini S. Carcinoma of the stomach: A review of epidemiology, pathogenesis, molecular genetics and chemoprevention. World J Gastrointest Oncol. 2012; 4: 156-69.

[5] Chen W, Zheng R, Zhang S, et al. Cancer incidence and mortality in China, 2013. Cancer Lett. 2017; 401: 63-71.

[6] Jiang G, Wen L, Zheng H, Jian Z, Deng W. miR-204-5p targeting SIRT1 regulates hepatocellular carcinoma progression. Cell Biochem Funct. 2016; 34: 505-10.

[7] Verbrugge I, Johnstone RW, Smyth MJ. SnapShot: Extrinsic apoptosis pathways. Cell. 2010; 143: 1192, e1-2.

[8] Schwabe RF, Luedde T. Apoptosis and necroptosis in the liver: a matter of life and death. Nat Rev Gastroenterol Hepatol. 2018; 15: 738-52.

[9] Riley T, Sontag E, Chen P, Levine A. Transcriptional control of human p53-regulated genes. Nat Rev Mol Cell Biol. 2008; 9: 402-12.

[10] Korkmaz G, Lopes R, Ugalde AP, et al. Functional genetic screens for enhancer elements in the human genome using CRISPR-Cas9. Nat Biotechnol. 2016; 34: $192-8$.

[11] Hafner A, Bulyk ML, Jambhekar A, Lahav G. The multiple mechanisms that regulate p53 activity and cell fate. Nat Rev Mol Cell Biol. 2019; 20: 199-210.

[12] Raycroft L, Wu HY, Lozano G. Transcriptional activation by wild-type but not transforming mutants of the p53 anti-oncogene. Science. 1990; 249: 1049-51.

[13] Walker KK, Levine AJ. Identification of a novel p53 functional domain that is necessary for efficient growth suppression. Proc Natl Acad Sci U S A. 1996; 93: 15335-40.

[14] Brady CA, Jiang D, Mello SS, et al. Distinct p53 transcriptional programs dictate acute DNA-damage responses and tumor suppression. Cell. 2011; 145: 571-83.

[15] Patel PI, Roa BB, Welcher AA, et al. The gene for the peripheral myelin protein PMP-22 is a candidate for Charcot-Marie-Tooth disease type 1A. Nat Genet. 1992; 1: 159-65.

[16] Snipes GJ, Suter U, Welcher AA, Shooter EM. Characterization of a novel peripheral nervous system myelin protein (PMP-22/SR13). J Cell Biol. 1992; 117: 225-38.

[17] Wang L, Mear JP, Kuan CY, Colbert MC. Retinoic acid induces CDK inhibitors and growth arrest specific (Gas) genes in neural crest cells. Dev Growth Differ. 2005; 47: 119-30.

[18] Winslow S, Leandersson K, Larsson C. Regulation of PMP22 mRNA by G3BP1 affects cell proliferation in breast cancer cells. Mol Cancer. 2013; 12: 156

[19] Karlsson C, Afrakhte M, Westermark B, Paulsson Y. Elevated level of gas3 gene expression is correlated with G0 growth arrest in human fibroblasts. Cell Biol Int. 1999; 23: 351-8.

[20] Re FC, Manenti G, Borrello MG, et al. Multiple molecular alterations in mouse lung tumors. Mol Carcinog. 1992; 5: 155-60.

[21] Evtimova V, Zeillinger R, Weidle UH. Identification of genes associated with the invasive status of human mammary carcinoma cell lines by transcriptional profiling. Tumour Biol. 2003; 24: 189-98.

[22] Mimori K, Kataoka A, Yoshinaga K, et al. Identification of molecular markers for metastasis-related genes in primary breast cancer cells. Clin Exp Metastasis. 2005; 22: 59-67. 
[23] Remondini D, O'Connell B, Intrator N, et al. Targeting c-Myc-activated genes with a correlation method: detection of global changes in large gene expression network dynamics. Proc Natl Acad Sci U S A. 2005; 102: 6902-6.

[24] van Dartel M, Hulsebos TJ. Characterization of PMP22 expression in osteosarcoma. Cancer Genet Cytogenet. 2004; 152: 113-8.

[25] Huhne K, Park O, Liehr T, Rautenstrauss B. Expression analysis of the PMP22 gene in glioma and osteogenic sarcoma cell lines. J Neurosci Res. 1999; 58: 624-31.

[26] Liu S, Chen Z. The Functional Role of PMP22 Gene in the Proliferation and Invasion of Osteosarcoma. Med Sci Monit. 2015; 21: 1976-82.

[27] Tawk M, Makoukji J, Belle M, et al. Wnt/beta-catenin signaling is an essential and direct driver of myelin gene expression and myelinogenesis. J Neurosci. 2011; 31: 3729-42.

[28] Both J, Wu T, Bras J, Schaap GR, Baas F, Hulsebos TJ. Identification of novel candidate oncogenes in chromosome region 17p11.2-p12 in human osteosarcoma. PLoS One. 2012; 7: e30907.

[29] van Dartel M, Cornelissen PW, Redeker S, et al. Amplification of 17p11.2 approximately p12, including PMP22, TOP3A, and MAPK7, in high-grade osteosarcoma. Cancer Genet Cytogenet. 2002; 139: 91-6.

[30] van Dartel M, Leenstra S, Troost D, Hulsebos TJ. Infrequent but high-level amplification of $17 \mathrm{p} 11.2$ approximately p12 in human glioma. Cancer Genet Cytogenet. 2003; 140: 162-6.

[31] Cai W, Chen G, Luo Q, et al. PMP22 Regulates Self-Renewal and Chemoresistance of Gastric Cancer Cells. Mol Cancer Ther. 2017· 16: 1187-98.

[32] Elmore S. Apoptosis: a review of programmed cell death. Toxicologic pathology. 2007; 35: 495-516.

[33] Ouyang L, Shi Z, Zhao S, et al. Programmed cell death pathways in cancer: a review of apoptosis, autophagy and programmed necrosis. Cell proliferation. 2012; 45: 487-98.

[34] Padmanabhan N, Ushijima T, Tan P. How to stomach an epigenetic insult: the gastric cancer epigenome. Nat Rev Gastroenterol Hepatol. 2017; 14: 467-78.

[35] Zhu J, Luo J, Li Y, et al. HMGB1 induces human non-small cell lung cancer cell motility by activating integrin alphavbeta3/FAK through TLR4/NF-kappaB signaling pathway. Biochem Biophys Res Commun. 2016; 480: 522-7.

[36] Danaei G, Vander Hoorn S, Lopez AD, Murray CJ, Ezzati M. Causes of cancer in the world: comparative risk assessment of nine behavioural and environmental risk factors. Lancet. 2005; 366: 1784-93.

[37] Ferlay J, Soerjomataram I, Dikshit R, et al. Cancer incidence and mortality worldwide: sources, methods and major patterns in GLOBOCAN 2012. Int J Cancer. 2012; 136: E359-86.

[38] Jang SW, Lopez-Anido C, MacArthur R, Svaren J, Inglese J. Identification of drug modulators targeting gene-dosage disease CMT1A. ACS Chem Biol. 2012; 7: 1205-13.

[39] Fabbretti E, Edomi P, Brancolini C, Schneider C. Apoptotic phenotype induced by overexpression of wild-type gas3/PMP22: its relation to the demyelinating peripheral neuropathy CMT1A. Genes Dev. 1995; 9: 1846-56. 